\title{
Correction to: Understanding firm exit: a systematic literature review
}

\author{
Elena Cefis · Cristina Bettinelli $\cdot$ Alex Coad \\ Orietta Marsili
}

Published online: 6 July 2021

(C) Springer Science+Business Media, LLC, part of Springer Nature 2021

\section{Correction to: Small Bus Econ https://doi.org/10.1007/s11187-021-00480-x}

We regret that due to an oversight in the editorial process the information concerning the paper by Kato, Onishi, Honjo in the second paragraph of section 4 and in Table 3 is inconsistent with the final version.

The sentence in the second paragraph of section 4 starting with Kato, Onishi, Honjo (this issue) should read "Kato, Onishi, Honjo (this issue) find that in Japanese manufacturing and information services sectors, new firms that have greater patent stock are less likely to exit by bankruptcy and more likely to exit by merger, and this pattern is consistent for both patent applications and granted patents.”.

The online version of the original article can be found at https://doi.org/10.1007/s11187-021-00480-x

\section{E. Cefis $(\bowtie)$}

University of Bergamo, Bergamo, and Sant'Anna School of Advanced Studies, Pisa, Italy

e-mail: elena.cefis@unibg.it

C. Bettinelli

University of Bergamo, Bergamo, Italy

A. Coad

Waseda Business School, Waseda University, Tokyo, Japan

O. Marsili

School of Management, University of Bath, Bath, UK
The entry in Table 3, in the first row and last column under the heading Main findings should read "Overall, new firms that have greater patent stock are less likely to exit by bankruptcy and more likely to exit by merger. These results are consistent for both patent applications and granted patents.".

The original article has been corrected

Publisher's note Springer Nature remains neutral with regard to jurisdictional claims in published maps and institutional affiliations. 